\title{
G20 서울 정상회의 이후 G20 개발의제 논의 현황
}

\author{
송 혜 령 외교통상부 개발정책과 1 등서기관
}

\section{목 차}

1. $\mathrm{G} 20$ 개발의제의 의의

2. G20 서울 정상회의이후 G20 개발그룹 활동 경과

3. 결 어

\section{G2O 개발의제의 의의}

2010년 G20 서울 정상회의는 서울 개발 컨센서스(Seoul Development Consensus)와 다년간 개발 행동계획을 주요 성과로 남김으로써 G20 뿐만 아니라 국제개발협력에 있어 하나의 이정표를 마련하 였다.1) 무엇보다도 서울 개발 컨센서스는 단순한 원조를 넘어 개도국 능력배양(capacity building) 을 통한 자생력 확충을 꾀하고, 선진국으로부터의 획일적 접근(one-size-fits-all)이 아닌, 국가별 로 고유한 상황에 부합하는 개발정책 추진을 지원할 것을 강조하였다. 서울 정상회의에서 합의한 $\mathrm{G} 20$ 개발의제의 의미를 아래와 같이 정리해 볼 수 있겠다.

첫째, 서울 정상회의에서 G20 개발의제의 기본 추진방향에 대해 처음으로 합의하는 등 G20내에서 개발의제가 주요 의제로 지속 논의될 수 있는 기반을 마련하였다. 주지하다시피, 2008년 글로벌 금

1) "다함께 성장을 위한 서울 개발 컨센서스(Seoul Development Consensus for Shared Growth)"는 G20 개발의제의 기 본 추진방향과 6 대 기본 원칙을 집약한 문서로서, 앞으로 $\mathrm{G} 20$ 개발의제의 기본헌장과 같은 역할을 할 것으로 기대된다 (서울 정상회의 문서 제54항 참조). G20의 6대 개발원칙은 $\triangle$ 경제성장과 성장복원력 중심의 개발의제 추진, $\triangle$ 당사국 주도의 개발정책 추진과 글로벌 개발 파트너십 구축, $\triangle$ 국제 · 지역 차원의 공동대응이 필요한 주제의 우선 추진, $\triangle$ 민 간부문 참여 촉진, $\triangle$ 기존 개발협력 논의와의 차별화 및 보완, $\triangle$ 이행가능한 행동계획을 통한 구체성과 도출로 구성된 다. 한편, 서울 개발 컨센서스를 뒷받침하기 위해 성장과 직접 연계된 9개 핵심 분야별로 구체적이며 실질적인 "다년간 개발 행동계획(Multi-Year Development Action Plan on Development)"을 함께 채택하였다. 9개 분야는 우리나라의 개발경험 등에 비추어 경제성장과 직접 연계된 분야로서, $\triangle$ 인프라, $\triangle$ 인적자원개발, $\triangle$ 무역, $\triangle$ 민간투자 및 고용창출, $\triangle$ 식량안보, $\triangle$ 성장복원력, $\triangle$ 금융소외계층 포용, $\triangle$ 국내재원 동원, $\triangle$ 개발경험 공유이다. G20의 기본 목표는 이러한 분야에서 저개발국의 지속가능한 성장에 대한 장애요소(bottleneck)를 해소하는 데 주력하고자 하는 것이다. G20 회원 국들이 제출한 개발공약(action plan) 중에서 상기 6대 개발원칙 등 G20 개발의제 추진 방향에 가장 부합되는 공약을 선정하여 망라한 결과물이 다년간 개발행동계획으로 최종 도출되었다. 다년간 행동계획에는 9 개 분야별로 구체 행동계 획, 이행 시한과 주체가 명시되어 있다. 
융위기에 대응하기 위해 태동한 G20은 금융분야 이슈 논의에 초점이 맞춰졌다. 금융위기가 진정국 면에 접어든 2010년 의장국을 수임하게 된 우리나라는 G20이 위기 이후(Post-Crisis)에도 지속적으 로 영향력을 유지하기 위해서는 정통성을 제고해야 하며, 이를 위해서는 G20 비회원국의 주요 관심 사안인 개발분야에서 성과를 도출해야 한다는 점에 착안하여 개발의제를 “코리아 이니셔티브”로 적 극 추진하였다2). 그 결과 2010년 6월 토론토 정상회의에서 G20 정상들은 서울 정상회의에서 개발의 제를 비중있게 논의하기 위해 G20 개발그룹(DWG: High-Level Development Working Group)을 발 족시키기로 합의했다. 이후 G20 개발그룹은 서울에서 두 차례 회의를 갖고, 서울 개발 컨센서스의 근간을 마련하였다. 다시 말해, 서울 정상회의는 G20 개발그룹이라는 공식 채널3)과 서울 개발 컨센 서스와 다년간 개발 행동계획으로 집약되는 G20 개발의제 체제를 성과물로 남기면서 G20 프로세스 에서 개발의제의 지속적인 논의 근거를 마련했다는 데 일차적인 의의가 있다.

둘째, G20 서울 정상회의 개발의제 추진 과정에서 우리나라는 개발문제가 단순한 원조 논의를 넘 어 글로벌 재균형(global rebalancing) 확립이라는 G20 차원의 정책목표 달성에도 기여할 것이라는 건설적인 방향을 제시하였다. 그 결과물인 서울 개발 컨센서스는 궁극적으로 개발논의의 지평 확대 를 가져왔다.

서울 정상회의 준비 당시 그간 세계 경제를 이끌어 온 선진국의 경기침체가 장기화될 우려가 대두 되면서 세계 경제를 주도할 새로운 성장동력 창출에 대한 관심이 고조되고 있었다. 즉, 중국, 브라 질, 인도네시아 등 신흥국뿐만 아니라 세계 경제 성장의 다극화를 통해 세계 경제의 재균형을 달성할 수 있다는 일각의 목소리가 반향을 일으키고 있었다4). 특히, G20의 정책목표인 강하고 지속가능한 균형성장(Framework for strong, sustainable and balanced growth) 달성을 위해서는 거시경제적 불균형뿐만 아니라, 개발격차를 해소하고 번영의 혜택을 공유하는 것이 중요하다는 점이 부각되고 있었다. 이러한 지적 모멘텀과 우리의 성공적인 개발경험을 바탕으로, 서울 개발 컨센서스는 단순한 원조를 넘어 개발에 대한 새로운 시각을 제시함으로써 개발의제 논의의 지평을 확대하였다.

2) 2010년 5월 세르파 회의시 우리측 제안을 토대로 개발의제 추진 및 개발그룹(DWG) 설치에 잠정 합의하였다. 당 시 세르파 회의를 앞두고 회람한 이슈페이퍼에서 우리는 기존 개발논의와의 보완, 유엔 MDG의 달성 촉진, G20 Framework과의 연계 등을 감안, 경제성장과 역량강화 중심의 개발의제 추진 방향을 제시하였다. 아울러, 토론토 정상회 의 이후 서울 정상회의에서 채택할 개발의제의 구체 논의를 위해 개발그룹을 창설할 것을 제안하였다. 특히, 우리는 개 발의제의 실질적인 당사자인 개도국 대다수가 G20 비회원국인 점을 감안, 이들의 목소리를 대변할 수 있도록 지역개발 은행을 개발그룹에 초청할 것도 제안하였다. 이러한 제안은 G20 회원국들의 폭넓은 지지를 통해 향후 G20 개발의제 논의 프로세스의 토대를 구축하는데 일조하였다.

3) G20 개발그룹은 서울 정상회의를 통해 향후 지속적인 활동근거를 확보하였다. G20 정상들은 서울 개발 컨센서스 채택 후 개발그룹의 임무를 종료하지 않고, 다년간 행동계획을 점검하고 개선하는 새로운 임무를 부여했다(서울 정상회의 문 서 제 54 항 참조).

4) 그 논리는 다음과 같다. 세계경제를 이끌어 왔던 선진국들이 금융위기로 인해 크게 타격을 입은 결과, 선진국들이 전 세계 경제성장을 다시 주도하기에는 상당한 시간이 소요될 전망이다. 따라서 전 세계 경제성장을 위해 필요한 새 로운 총수요는 신흥국들의 소비 증가와 저개발국으로의 투자 확대를 통해 보완될 가능성이 크다. 따라서 개발은 단순 히 저개발국의 빈곤해소를 넘어 글로벌 경제의 재균형 (global rebalancing)과 성장을 위해서도 반드시 필요한 과제 로 간주되어야 하는 것이다. Kemal Dervis가 2009년말 Financial Times에 기고한 글에서도 이와 유사한 요지의 내용을 확인할 수 있다(“Developing economies can help cure global imbalances", Financial Times, 2009.12.20). 
셋째, 이러한 시각의 연장선상에서, 그간 수원국으로 통칭되어온 개도국은 이제 원조의 단순한 수 혜자가 아니라, 세계 경제의 지속가능한 성장을 달성하는데 기여하는, 즉 선진국과 동등한 파트너 국 가로 자리매김하게 되었다. 서울 개발 컨센서스는 하나의 선진적인 정책이나 시스템을 만병통치약 (one-size-fits-all)식으로 강조하거나, 일방적으로 이식하는 개발협력방식이 이제 유효하지 않다는 점을 분명히 밝히고 있다. G20 개발공약이 남북협력, 남남협력, 삼각협력 등 다양한 협력방식을 인 정하고 있는 것도 이러한 인식에 바탕을 둔 것이다. 즉, G20은 성공적인 개발에 이르기까지 다양한 경로가 존재하고 있다는 점을 강조하고, 당사국간 개발지식과 경험 공유 활성화를 도모한다. 이는 국 제개발협력에 있어 효율적인 다극화의 필요성을 선언한 것으로도 해석해 볼 수 있다. 이런 의미에서, 오랫동안 비주류적 개발협력방식이었던 남남협력 이슈가 최근 부각되고 있는 데에는 중국 등 신흥국 의 강력한 부상뿐만 아니라 G20 개발의제를 통한 논의의 공식화에도 힘입은 바가 크다.

넷째, 글로벌 개발협력체제의 분절화 심화, 선진공여국의 원조 피로감 증대, 글로벌 금융위기 등 으로 인한 $\mathrm{ODA}$ 감소 우려 등 개발위기가 대두되는 중요한 시점에서, G20 개발의제의 등장은 개발협 력의 중요성을 새롭게 부각시키는 모멘텀을 제공하는 한편, 의제 추진 과정에서 기존의 개발논의에 상당한 시사점과 과제를 안겨주었다고 볼 수 있다. 무엇보다, 서울 개발 컨센서스 추진과정에서 G20 은 기존 개발논의의 문제점 등을 검토한 토대 위에서, 기존 체제의 엔트로피를 증가시키지 않고 부가 가치를 창출하는 방식으로 작업하였다. 기존 개발협력과의 차별화 및 보완을 통한 분업방식(division of labor)의 공식적 선언과 도입(서울 개발 컨센서스 제 5 원칙)은 이를 입증한다.

한편, G20으로서는 기존 논의와의 차별화를 추진함에 있어 국제경제협력의 최상위 논의의 장이라 는 정체성에 부합하는 한편, 기존 $\mathrm{G} 7$ (원조재원), 유엔(사회개발), $\mathrm{OECD}$ (원조효과성) 등과 대별되는 방식의 개발협력체제를 추진해야 하는 선택지가 주어졌다고 볼 수 있다. 결국 G20은 지속가능한 경 제성장과 관련된 포괄적 역량강화를 개발협력의 우선적인 목표로 선정하였다. 개발공약의 내용 측면 에서는, 인프라를 우선 핵심분야로 선정함으로써 인프라 지원 논의를 활성화할 수 있는 기반을 조성 한 것이 대표적이다. 아울러, 단순한 양적 수치 달성을 위해 질주하는 경제성장이 아닌, "포용적인 (inclusive)", "복원력(resilience)" 있는 성장을 추구한다는 포부는 60년대 이후 축적된 개발협력 역 사의 학습효과라고 할 수 있다. 또한, G20이 원조재원클럽이 아닌 정책조율 메커니즘에 집중하는 것 도 G7과의 차별성을 꾀한 결과이다.

\section{G20 서울 정상회의이후 G20 개발그룹 활동 경과}

\section{가. G20 개발그룹의 개관}

G20 개발그룹 회의에 대한 참여범위는 G20 세르파(Sherpa) 회의와 같이 G20 회원국과 초청국으 
로 한정된다. 다만, G20 개발그룹에 대해 전문적인 자문을 제공하도록 유엔 등 국제기구, 다자개발 은행 등으로 구성된 기술자문그룹(TSG: Technical Support Group)이 산하에 설치되어 있다5). 이를 통해 G20 개발그룹 논의가 다양한 국제기구와 공유됨으로써 논의의 투명성 뿐만 아니라 대표성을 유지할 수 있도록 하였다. 또한, 인프라 분야 경우 고위급 민간자문위원으로 구성된 별도의 패널 (HLP: High-Level Panel)6)을 설치함으로써 G20 개발의제에 있어 인프라 분야의 중요성을 실질적 으로 부각하는 한편, 논의의 전문성을 보다 강화하였다.

2010년 11월 서울 개발 컨센서스와 다년간 행동계획 채택 이후 G20 개발그룹은 총9개 분야 공약 에 대한 이행과 점검을 주요 임무로 부여받았다. G20 개발그룹 소관분야의 방대성을 감안, 효과적인 이행 점검을 위해 분야별로 조정국가(co-facilitator)와 주력 국제기구(lead IO)가 선정되었다. 일례 로, 우리나라는 인프라, 인적자원개발(HRD) 및 개발경험분야에서 조정국가로 활동중이다7). 국제기 구의 경우, 인프라는 세계은행, $\mathrm{HRD}$ 는 $\mathrm{OECD}$ 및 $\mathrm{ILO}$, 개발경험공유는 $\mathrm{UNDP}$ 를 주력 기구로 선정하 는 등 각 국제기구의 전문성과 9 개 분야간 업무분장의 균형을 도모하였다.

한편, G20 개발그룹은 세르파 산하에 설치되었다. 따라서, 개발그룹 논의사항은 세르파 회의에 보 고되어 승인된 후 최종적으로 G20 정상회의에 제출된다(아래 도표 참조).

〈도표 1〉 G20 DWG 회의와 세르파 회의간 업무 흐름도(2011년 기준)

\begin{tabular}{|c|}
\hline 3월 DWG 회의 \\
\hline $\begin{array}{c}\text { 기본추진방향 및 금년도 } \\
\text { 작업계획안 합의 }\end{array}$ \\
\hline DWG 작업계획안 제출 \\
\hline
\end{tabular}

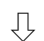

\begin{tabular}{|c|}
\hline 세르파 회의 \\
\hline 작업계획 점검 및 승인 \\
\hline
\end{tabular}
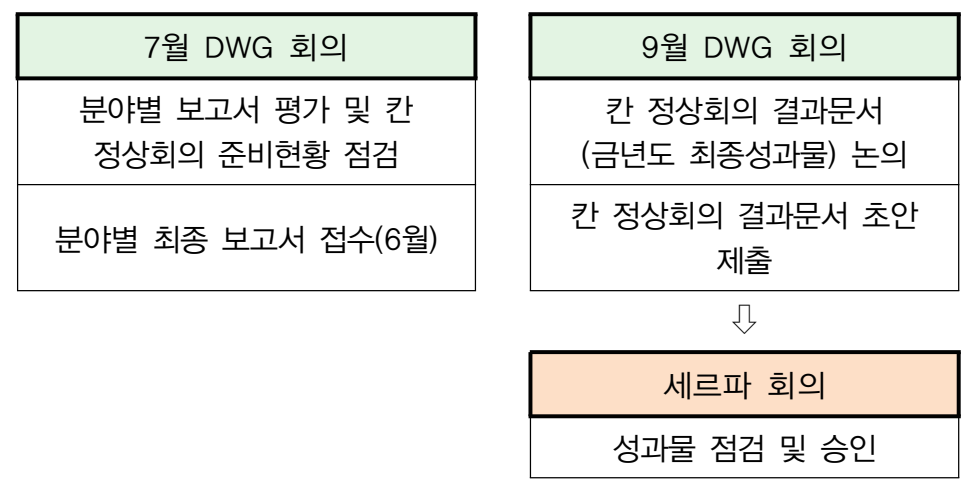

5) G20 초청국은 사전에 합의된 기준(지역협의체 순환의장국 등)과 당해 연도 의장국 권한에 따라 선정된다. 금년도 의장 국인 프랑스는 UAE, 싱가포르, 에티오피아, 적도기니 및 스페인을 초청하였다. TSG에 참여하는 국제기구는 2010년 경 우 유엔, $\mathrm{OECD}$, 세계은행 및 지역개발은행(ADB, AfDB, IDB, IsDB) 등 총 10개 기구에 한정되었으나, 금년 경우 다년 간 행동계획에 명시된 국제기구를 망라하는 등 참여가 대폭 확대되었다. 그 결과, $\mathrm{G} 20$ 개발의제 논의에는 개발분야 유 수의 국제기구 대부분이 참여하고 있다.

6) HLP는 인프라 재원 조성 방안, 세계은행 등 “다자개발은행의 인프라 행동계획”(다년간 개발 행동계획 인프라 분야 공약 중 하나) 등을 검토할 목적으로 활동한다. 코트디브아르 개발부 장관을 역임한 바 있는 Thiam 영국 프루덴셜 CEO가 의장을 수임하고 있으며, 우리나라의 조윤제 교수(서강대)를 비롯하여, G20 회원국에서 추천한 16 명의 위원이 활동하고 있다.

7) 다년간 행동계획 9 개 분야에 대한 회원국들의 폭넓은 참여를 유도하기 위해 DWG 공동조정국 체제가 G20 서울 정상회 의 준비과정에서부터 확립되었다. 공동조정국은 G20 회원국들의 자발적 참여를 전제로, 각국의 관심사항, 전문성, 지 역적 배분 등을 종합적으로 고려하여, G20 개발그룹 공동의장국(2010년 한국 및 남아공/2011년 한국, 프랑스 및 남아 공)이 선정한다. 인프라 분야 경우 한국, 미국, 터키 및 프랑스, $\mathrm{HRD}$ 분야는 한국, 러시아 및 아르헨티나, 그리고 개발 경험공유 분야는 한국 및 멕시코가 공동조정국을 수임중이다. 


\section{나. G20 개발그룹 논의 현황(2011년 상반기)}

G20 의장국에서 유관회의를 개최하는 관행에 따라 금년도 G20 개발그룹 1 차 회의는 지난 3 월 파 리에서 개최되었다. G20 서울 정상회의 이후 처음으로 개최된 동 회의에서는 서울 정상회의 합의사 항의 후속조치 차원에서 서울 개발 컨센서스 및 다년간 개발 행동계획의 이행 경과를 점검하는 한편, 칸 정상회의 준비의 일환으로 향후 작업계획에 대한 회원국들의 합의를 형성하는 데 주력하였다. 특 히, 서울 정상회의에서 합의한 대로, 칸 정상회의에서 9 개 개발 분야 중에서도 인프라와 식량안보를 우선과제(priority)로 추진할 것을 재확인하고, 구체 작업계획에 합의하였다. 일례로, 금년도 G20 의 장국인 프랑스는 G20 인프라 고위급 패널(HLP) 활동의 본격 개시와 G20 농업장관회의의 최초 개최 추진 등을 통해 인프라와 식량안보 분야에서의 실질적인 성과 창출에 전력을 다할 계획임을 밝혔다.

\section{〈도표 2〉다년간 개발 행동계획 9 개 분야 핵심 요지}

- 인프라 투자 확대를 위한 고위급 패널(HLP) 창설 및 관련 제도 개선

- 개도국 노동자의 생산성 향상을 위한 직업기술 개발 및 국가전략 강화 지원

- 무역을 통한 성장을 지원하기 위해 개도국 무역역량 개선

- 개도국의 고용 관련 부가가치를 창출하는 민간투자 촉진

- 식량안보 정책 조율 강화 및 식량가격 변동성 완화

- 경제위기 대응과 복원력 제고를 위한 사회안전망 강화 및 송금비용 완화

- 중소기업 등 금융소외계층의 금융접근성 개선

- 조세역량배양을 통한 개도국의 개발재원 확충

- 다양한 개발경험을 공유하여 개도국 실정에 맞게 적용 추진

이어 6월말 남아공 케이프타운에서 개최된 G20 개발그룹회의에서는 지난 상반기 동안의 작업계획 이행경과를 평가하는 한편, 금년 6월 최종 보고서 제출 시한이 도래한 여러 분야(식량안보, 개발경험 공유 등)를 중심으로 G20의 최종 성과물을 점검하였다. 특히, 금년도 우선 과제인 인프라와 식량안 보의 경우 괄목할 만한 진전을 보였다. 우선, 6 월초 HLP 1차 회의가 런던에서 개최되어 활동을 본격 화하였을 뿐만 아니라, 케이프타운 회의와 연계하여 인프라 컨퍼런스가 개최됨으로써 G20 개발의제 중 인프라 분야의 중요성을 재확인하였다. 식량안보 또한 동 개발그룹 회의 직전 파리에서 개최된 G20 농업장관회의에서 가격변동성 관련 정보 공유 시스템(AMIS: Agricultural Market Information System) 구축 추진 등 가시적인 성과가 도출되었다8). 이러한 성과를 기반으로, 개발그룹에서는 식

8) 한편, G20 농업장관회의 아젠다의 모태가 사실상 G20 다년간 행동계획 식량안보 분야라는 점에서 G20 개발의제의 의 의가 확인되었다. 
량위기시 취약계층 보호 등 개발과 밀접하게 연계된 식량안보 이슈 논의에 보다 집중할 수 있었다.

이러한 일련의 논의 과정에서 우리나라는 전년도 G20 의장국으로서 서울 개발 컨센서스를 주도했 던 지적 자산과 G20 개발그룹 공동의장국(외교부 개발협력국장 수임)으로서의 입지를 적극 활용하 여, 효과적인 논의 전개에 기여하였다. 아울러, 3 개 분야 공동조정국 활동을 사실상 주도함으로써 9 개 분야의 균형있는 진전에 실질적으로 기여하였다. 일례로, 최종 보고서 제출시한이 2014년인 관계 로 중장기 이행과제로 분류되는 HRD 분야에서 금년중에도 가시적 성과를 도출할 수 있도록 ILO, $\mathrm{OECD}$ 등 유관 국제기구와의 공동작업을 주도하였다. 그 결과, 직업기술 지표(skills indicators) 작 업의 초안 마련, 저소득국가의 기술훈련전략 지원을 위한 시범국가의 조기 선정(방글라데시, 말라위, 베냉 등) 등의 성과를 거두었다. 또한, 9 개 분야간 상호 연계성(interconnectedness)를 염두에 둔 공 약 이행 추진을 통해 G20 개발의제 추진의 시너지를 창출할 수 있도록 독려하였다.

한편, 6 월 개발그룹 회의에서 프랑스측은 9 월 중순 $\mathrm{G} 20$ 재무-개발장관 합동회의를 개최한다는 계 획을 발표하였다. 동 합동회의는 G20 차원에서 처음으로 개최되는 회의인 바, 개발분야에 있어 칸 정상회의의 최종 성과물을 재무-개발 라인을 통해 포괄적으로 준비한다는 데 의의가 있다. 이를 통 해 G20 프로세스 안팎에서 G20 개발의제의 위상이 보다 강화될 것으로 기대된다.

지금까지의 논의 현황을 살펴볼 때, 금년 11 월 칸 정상회의에서는 인프라와 식량안보 분야를 중심으 로 대표적인 성과물이 발표될 것으로 예상된다. 이 과정에서, 개발에 대한 G20 회원국 공동의 비전뿐 만 아니라, 의장국인 프랑스의 핵심 관심사항이 정치적 메시지로 도출될 것이다. 그러나 무엇보다도, 9 개 분야 다년간 행동계획의 충실한 이행이 가장 기본적인 임무이자 최고의 성과물이 될 것이다.

\section{다. 서울 개발 컨센서스의 논의 확산과 공고화 작업}

우리나라는 작년에는 G20 의장국으로서 서울 개발 컨센서스 도입을 주도하였으며, 금년 들어서는 서울 개발 컨센서스의 논의 확산과 공고화 작업에 주력하고 있다.

국제 개발 커뮤니티에서 금년도 논의는 지난 5 월 이스탄불에서 개최된 제 4 차 유엔 최빈개도국 회 의(LDC-IV)와 오는 11월 부산 세계개발원조총회(HLF-4)를 통해 모멘텀을 형성하고 있다고 볼 수 있다.

이에 우리나라는 이스탄불 최빈개도국 회의 결과문서에 G20 개발의제를 반영하는 작업을 우선 추 진하였다. G20 회원국들과의 공조와 개도국들의 포괄적인 지지에 힘입어 서울 개발 컨센서스와 다 년간 개발 행동계획은 국제개발협력의 핵심사례 중 하나로 명시될 수 있었다.

이스탄불 회의에서 거둔 성과는 유엔 문서에서 서울 개발 컨센서스가 공식 반영되었다는 데 일차 적인 의의가 있다. 하지만, 이를 통해 향후 국제개발논의에서 서울 개발 컨센서스의 논의 확산, 즉 $\mathrm{G} 20$ 개발의제의 대표성 확보를 꾀할 수 있는 기반을 조성하였다는 데 더 큰 의미가 있다.

아울러, 유엔과의 연계성 강화는 G20 개발의제의 대표성 확보뿐만 아니라, 국제사회의 합의된 개 
발목표인 MDG 이행과 서울 정상회의 개발의제간 내용적인 연계성을 고려할 때도 중요하다. 일례로, $\mathrm{MDG}$ 달성 성과를 점검하기 위해 2010년 9월 뉴욕에서 개최된 MDG 고위급회의에서는 MDG 달성 촉진을 위한 지속가능한 경제성장의 중요성이 최종 합의문에 반영되었다9). 이러한 내용은 서울 개발 컨센서스 추진에 있어 동력이 되었다. 포용적이고 지속가능한 경제성장 촉진이라는 G20 개발의제의 방향에 대해 국제사회의 공감대를 형성할 수 있는 단초가 마련되었기 때문이다. 이런 측면을 감안하 여, 우리나라는 MDG 고위급회의 이후 유엔총회에서 경제성장 결의안 채택을 주도하기도 하였다.

한편, 오는 11월 부산 총회(HLF-4)에서는 개최국으로서의 입지를 활용하여 부산 총회 논의와 G20 개발의제간 연계성을 강화하는 데 주력하고 있다. 원조효과성 이슈를 넘어 개발효과성 등 향후 개발논의의 패러다임을 확장하는 무대로서 부산 총회의 위상이 격상된 것도 G20 개발의제를 추진했 던 우리나라의 지적 리더십에 기인한다. 부산 총회 준비작업의 일환으로 금년 하반기에는 G20과 부 산 총회간 의제 연계성 강화를 위한 일련의 워크숍이 예정되어 있다.

\section{3. 결 어}

국제사회에서 개발이슈는 최근 10 년간 유엔 $\mathrm{MDG}$ 달성을 위한 논의에 집중되어 왔다고 볼 수 있 다. MDG는 전반적인 지표가 개선되는 추세임에도 불구하고, 2015년까지의 목표시한을 감안할 때 이 행 속도가 부진하고, 목표별 이행상황이나 국가별 - 지역별 달성 성과도 편차가 심한 것으로 알려져 있다. 최근 식량 및 금융위기의 여파로 2015년까지 MDG 달성이 더욱 큰 어려움에 봉착했다는 전망 이 우세하다. 그 결과, 일각에서는 2015년 이후 Post-MDG 논의 필요성을 조심스럽게 제기하고 있 는 실정이다.

이러한 상황에서 G20 개발의제, 즉 서울 개발 컨센서스는 국제 개발논의에 있어 고양이 목에 방울 을 다는 역할을 했다고 볼 수도 있다. 특히, 60 70년대 실패로 각인된 정책적 경험이후 인프라 분야 의 재발견, 경제성장 이슈와 MDG간 접목 시도 등은 G20이 아니라면 공론화되기 어려운 주제였다. 남남협력의 담론화가 확대되는 것도 글로벌 개발 무대에서 신흥국의 영향력 확대와 함께 G20이 이 러한 담론의 가장 확고한 공식채널의 역할을 하고 있기 때문이다. 결과적으로, G20이 암묵적인 목표 로 삼은 “정책변화(policy impact)”에 있어 일정 성과를 보인 것이라고 평가할 수 있다.

그리고 이러한 과정에서 우리나라의 역할은 간과될 수 없다. 2010년 G20 서울 개발 컨센서스 채 택, 유엔 경제성장 결의안 추진, 2011년 부산 세계개발원조총회에서의 개발효과성 논의 촉발 등 최근 국제개발협력 논의 과정에서, 우리나라는 선진국, 신흥국, 그리고 개도국간 가교 역할(bridging role) 뿐만 아니라 사실상 규범 창설자(rule-setter)로서의 역할까지 담당하고 있다. 이러한 지적 리

9) $\mathrm{MDG}$ 고위급회의 결과문서에서는 지속적 · 포용적 · 공평한 경제성장(sustained, inclusive and equitable economic growth), 빈곤퇴치 및 지속가능한 개발을 추진 목표로 설정하였다. 
더십의 밑바탕에는 허언이 아닌 우리의 성공적인 개발경험이 깔려 있다.

G20이 신흥국을 포괄하는 유일무이의 협의체로서의 위상을 보유하고 있다는 점을 감안할 때, G20 개발그룹의 공동의장국인 우리나라의 지적 리더십은 실천적인 책임으로까지 이어져야 한다. 무엇보 다도, G20이 앞으로도 다년간 개발 행동계획이라는 개발공약을 충실히 이행하도록 독려함으로써 $\mathrm{G} 20$ 개발의제에 대한 국제사회의 신뢰도를 제고하는 데 기여해야 할 것이다.

이에 더 나아가, G20 개발협력체제가 양자 개발협력 채널, UN, OECD 등의 다자협력체제가 지닌 한계를 극복하고, 개발의 효과성, 효율성, 대표성을 어느 정도 구축할 것인가는 중장기적인 과제이 다. 우리는 G20 개발의제의 주도자로서, G20이 다양한 개발협력 주체들과 개발협력 방식들을 포괄 하는 새로운 국제 개발협력 패러다임을 창출해 가는데 있어 결정적 역할을 할 수 있도록 우리의 지적 기여를 배가해 나가야 할 것이다. 